\title{
Heterogeneidade institucional e o ingresso de investimento direto estrangeiro na economia brasileira
}

\author{
Geraldo Moreira Bittencourt \\ Professor - Universidade Federal de Juiz de Fora/Campus Governador Valadares (UFJF/GV) \\ Endereço: Avenida Dr. Raimundo Monteiro Rezende, 330 - Centro - Governador Valadares/MG \\ CEP: 35010-177 - E-mail: geraldo.bittencourt@ufjf.edu.br
}

\section{Leonardo Bornacki de Mattos}

Professor - Universidade Federal de Viçosa

Endereço: Av. Peter Henry Rolfs, s/n - Campus Universitário Viçosa/MG

CEP: 36570-000 - E-mail: Ibmattos@ufv.br

João Eustáquio de Lima

Professor - Universidade Federal de Viçosa

Endereço: Av. Peter Henry Rolfs, s/n - Campus Universitário - Viçosa/MG

CEP: 36570-000 - E-mail: jelima@ufv.br

Recebido em 25/02/2015. Aceito em 11/01/2016.

\section{Resumo}

Diante da evolução do ingresso de investimento direto estrangeiro na economia brasileira e da crescente preocupação com aspectos institucionais nos países receptores e de origem deste tipo de investimento, o presente estudo se propôs a avaliar como a qualidade do ambiente institucional e sua heterogeneidade tem afetado a entrada de IDE no mercado brasileiro, no período de 1996 a 2012. Para tanto, foram realizadas estimações de uma equação gravitacional para os fluxos de investimentos externos destinados ao Brasil e provenientes dos seus 31 principais parceiros investidores. Os resultados obtidos evidenciaram que o volume entrante de investimento externo no Brasil é positivamente afetado pela qualidade do ambiente institucional político-social e econômico-financeiro entre os países de origem e o Brasil. Além disso, a disparidade institucional econômico-financeira mostrou-se negativamente relacionada com o ingresso do capital externo.

\section{Palavras-Chave}

Investimento direto estrangeiro (IDE). Ambiente institucional. Brasil.

\begin{abstract}
Given the evolution of the inflow of foreign direct investment in the Brazilian economy and the growing concern about institutional aspects in the countries that receiving and sending this type of investment, the present study aimed to evaluate how the quality of the institutional environment and its heterogeneity has affected the entry of FDI in the Brazilian market in the period 1996-2012. Therefore, estimation of a gravity equation for the flow of foreign investments to Brazil and from its 31 major investment partners were held. The results of this analysis showed that the volume of incoming foreign investment in Brazil is positively affected by the quality of the socio-political and economic-financial institutional environment between the countries of origin and
\end{abstract}


Brazil. Moreover, the economic and financial institutional heterogeneity proved to be negatively related to the inflow of the foreign capital.

\section{Keywords}

Foreign direct investment (FDI). Institutional environment. Brazil.

\section{JEL Classification}

F2.

\section{Introdução}

Em uma economia aberta e globalizada, com empresas transnacionais operando em diferentes mercados, alterações na rentabilidade relativa resultam na realocação da produção para aqueles países mais competitivos. Deste modo, a análise do ingresso do investimento direto estrangeiro (IDE) deve levar em consideração tanto as variáveis microeconômicas, diretamente ligadas ao desempenho da firma, quanto as variáveis macroeconômicas e institucionais, que evidenciam os fatores específicos do país receptor do IDE.

Em relação aos aspectos institucionais, segundo North (1990), estes envolvem o conjunto de restrições criadas pela sociedade e que regulam a interação humana. Conforme este autor, as instituições podem ser classificadas como formais (regras criadas pela sociedade) ou informais (convenções e códigos de conduta), sendo as formais passíveis de alterações em menor tempo se comparadas às informais. O termo instituições também é referido como um conjunto de regulamentações, leis e políticas que afetam os incentivos econômicos e, assim, a disposição das firmas, nacionais e multinacionais, para investir em tecnologia, capital físico e humano (Acemoglu et al., 2005). Estes aspectos demonstram que ambientes institucionais fortes nos países de destino atraem maiores níveis de IDE (Wei, 2000; Rodrik et al., 2004; Bénassy-Quéré et al., 2007; Daude e Stein, 2007), ao passo que a má qualidade institucional dos potenciais países receptores do IDE é comumente citada como a principal explicação para a redução de fluxos de investimentos para países emergentes (Lucas, 1990; Alfaro et al., 2008; Papaioannou, 2009). 
Adicionalmente, conforme a análise do World Development Report (WDR), publicado pelo World Bank (2005), a busca por melhorias no ambiente de investimento, em determinado país, deve ser entendida como um processo e não como um evento isolado. Desse modo, diante da necessidade de revisão das políticas, muitos países estão criando instituições de apoio para auxiliar em tarefas específicas e sustentar os níveis de investimentos por meio de mudanças nas ações do governo. Essas instituições podem assumir várias formas, mas desempenham o papel de facilitar as consultas públicas, a revisão da legislação e das políticas existentes, além das novas propostas regulatórias.

Outra questão que vem sendo abordada é a verificação do efeito da distância ou heterogeneidade ${ }^{1}$ institucional entre os países de origem e destino dos fluxos de investimentos estrangeiros e comércio, o que, segundo Habib e Zurawicki (2002), De Groot et al. (2004) e Bénassy-Quéré et al. (2007), representaria custos de transação adicionais e funcionaria como restrição significativa ao ingresso de IDE e às transações comerciais. Neste contexto, surgem os questionamentos a respeito do papel das instituições e sua heterogeneidade sobre os fluxos de investimento direto externo.

Em relação ao Brasil, a partir de 1996, como pode ser visualizado na Figura 1, houve um acentuado crescimento do ingresso de IDE na sua economia, o qual atingiu o patamar de US\$32,8 bilhões no ano 2000. Apesar da queda na entrada de investimento externo no mercado brasileiro, no período entre 2001 e 2003, motivada, principalmente, pelo declínio dos processos de privatizações, pela crise energética nacional, queda nas bolsas dos Estados Unidos da América (EUA) e o desaquecimento da economia global, o ingresso de IDE retomou seu crescimento no período entre 2004 e 2008. No ano de 2009, a crise financeira mundial provocou uma redução no volume entrante de investimento direto estrangeiro no Brasil, mas já no ano seguinte houve uma retomada na elevação do ingresso de IDE, o qual atingiu seu ápice em termos nominais, no valor de US\$ 69,5 bilhões, no ano de 2011 (Figura 1). Ano em que, de acordo com o relatório da CEPAL (2011), os fluxos de IDE na América Latina e Caribe alcançaram US\$ 153,4 bilhões, sendo a América do Sul responsável pelo

\footnotetext{
${ }^{1}$ Conforme Berry et al. (2010), os países são distantes uns dos outros, não só pela distância geográfica, mas, também, porque as diferenças (heterogeneidades) institucionais, sociais, culturais ou políticas aumentam os custos de transação, as incertezas e dificuldades para que as firmas multinacionais operem além de suas fronteiras nacionais.
} 
recebimento de US\$121,2 bilhões (79\%) e o Brasil se classificando como o maior receptor, com um montante equivalente a $45,3 \%$ do total da região latina.

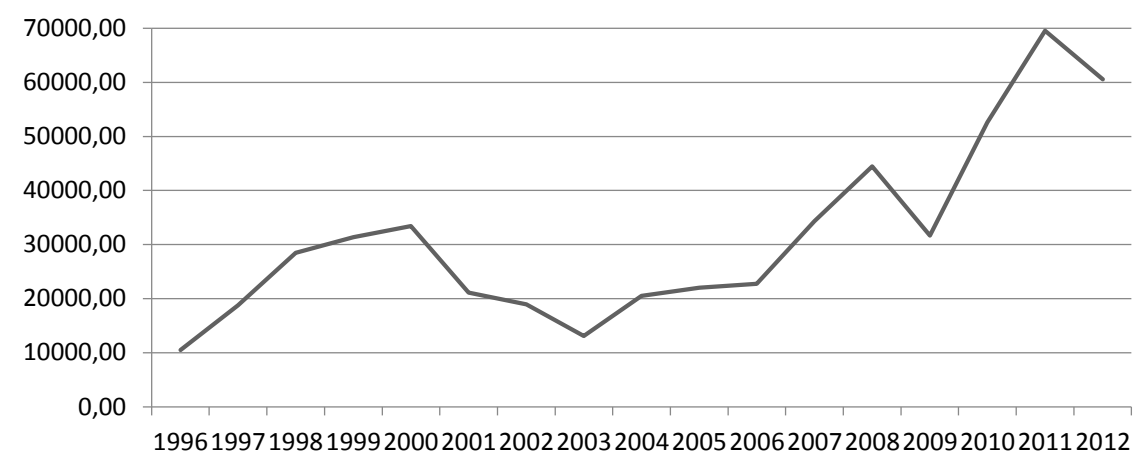

Figura 1 - Ingresso de IDE, em milhões de dólares (US\$), no período de 1996 a 2012

Fonte: Elaborado pelos autores a partir de dados do Banco Central do Brasil (BCB, 2013).

No que tange aos países de origem do IDE destinado à economia brasileira (Tabelal), no ano de 2010, por exemplo, com um investimento de US\$ 8,6 bilhões, Luxemburgo foi o principal investidor, alcançando $16,4 \%$ do total do IDE recebido pelo Brasil, em seguida, vieram: Países Baixos (12,7\%), Suíça (12,2\%) e Estados Unidos (11,8\%). Já em 2011, os Países Baixos retomaram a liderança perdida em 2009, alcançando $25,2 \%$ do total de IDE entrante no Brasil, o que representou quase o dobro do valor investido pelos Estados Unidos $(12,8 \%)$, que ocupou a segunda colocação, seguido por Espanha (12,3), Japão $(10,8)$, França $(4,4 \%)$, Reino Unido (3,9\%), entre outros. Em 2012, os Estados Unidos e Países Baixos lideraram o ranking de IDE destinado ao Brasil, alcançando 20,3\% e 20,1\% do montante recebido, respectivamente. 
Tabela 1 - Ingresso total de IDE no Brasil e distribuição por país de origem dos recursos, em US\$ milhões, período 2009 a 2012

\begin{tabular}{lrlrlrlr}
\hline País & 2009 & País & 2010 & País & 2011 & 2012 \\
\hline Total & 31.679 & Total & 52.607 & Total & 69.530 & Total & 60.543 \\
Países Baixos & 6.514 & Luxemburgo & 8.638 & Países Baixos & 17.582 & EUA & 12.310 \\
EUA & 4.901 & Países Baixos & 6.695 & EUA & 8.910 & Países Baixos & 12.213 \\
Espanha & 3.424 & Suíça & 6.437 & Espanha & 8.593 & Luxemburgo & 5.965 \\
Alemanha & 2.472 & EUA & 6.204 & Japão & 7.536 & Suíça & 4.333 \\
França & 2.140 & França & 3.421 & França & 3.086 & Espanha & 2.523 \\
Japão & 1.672 & Áustria & 3.325 & Reino Unido & 2.749 & França & 2.155 \\
Canadá & 1.371 & Japão & 2.497 & Hong Kong & 2.077 & Chile & 2.013 \\
Ilhas Cayman & 1.091 & Noruega & 1.535 & Luxemburgo & 1.867 & Reino Unido & 1.978 \\
Reino Unido & 1.032 & Espanha & 1.491 & Canadá & 1.789 & Canadá & 1.950 \\
Chile & 1.026 & Portugal & 1.193 & Áustria & 1.508 & Japão & 1.471 \\
\hline
\end{tabular}

Fonte: Elaborado pelos autores a partir de dados do Banco Central do Brasil (BCB, 2013).

A partir desta análise dos ingressos de IDE no mercado brasileiro, verifica-se que a entrada deste capital aumentou fortemente nos últimos anos, apesar da queda no ano de 2012. Ressalta-se, também, a ampla participação do capital proveniente de economias desenvolvidas. Portanto, uma questão importante a ser tratada é de que forma a caracterização da estrutura institucional dos países de origem e destino dos investimentos diretos estrangeiros impacta os fluxos destes investimentos.

Conforme dados apresentados na Tabela 2, formada por um grupo de países que representam a origem de grande parte do IDE destinado à economia brasileira, verifica-se que no Brasil há espaço para grandes avanços institucionais, uma vez que a qualidade do ambiente institucional, mensurada pela média dos indicadores propostos por Kaufmann et al. (2009), ${ }^{2}$ é inferior à verificada para os países desenvolvidos apresentados, a exemplo dos Estados Unidos, Luxemburgo, Países Baixos, e França, que estão entre os principais mercados de origem do IDE. Os dados apresentados na Tabela 2 também revelam certa heterogeneidade institucional entre o Brasil e os países de

2 Esses indicadores medem aspectos como nível de democracia, estabilidade política, efetividade das políticas governamentais, qualidade regulatória, cumprimento da lei e controle da corrupção e variam entre -2,5 e 2,5 sendo que valores mais elevados estão associados à maior qualidade institucional. 
origem do IDE, o que sugere que a economia brasileira pode estar sujeita a maiores custos de transação provenientes da baixa qualidade institucional relativa, o que indicaria a necessidade de esforços para a melhoria desses indicadores.

Tabela 2 - Qualidade do ambiente institucional em países desenvolvidos e em desenvolvimento selecionados, período de 2008 a 2012

\begin{tabular}{|c|c|c|c|c|c|}
\hline \multirow[t]{2}{*}{ País } & \multicolumn{5}{|c|}{ Ambiente Institucional } \\
\hline & 2008 & 2009 & 2010 & 2011 & 2012 \\
\hline Argentina & $-0,29$ & $-0,38$ & $-0,28$ & $-0,22$ & $-0,35$ \\
\hline México & $-0,18$ & $-0,18$ & $-0,19$ & $-0,13$ & $-0,12$ \\
\hline Brasil & $-0,03$ & 0,05 & 0,11 & 0,09 & 0,05 \\
\hline Chile & 1,12 & 1,13 & 1,19 & 1,21 & 1,19 \\
\hline França & 1,25 & 1,27 & 1,27 & 1,21 & 1,18 \\
\hline Estados Unidos & 1,18 & 1,18 & 1,20 & 1,23 & 1,25 \\
\hline Países Baixos & 1,63 & 1,65 & 1,65 & 1,71 & 1,72 \\
\hline Luxemburgo & 1,69 & 1,69 & 1,71 & 1,75 & 1,71 \\
\hline
\end{tabular}

Fonte: Elaborado pelos autores a partir de dados do World Bank (2013).

Portanto, considerando o cenário de evolução do ingresso de IDE na economia brasileira e o ambiente institucional do Brasil e dos diversos países de origem ${ }^{3}$ desse investimento, o objetivo geral deste trabalho é verificar os impactos do ambiente institucional e sua heterogeneidade sobre os fluxos de investimentos estrangeiros ingressantes na economia brasileira no período de 1996 a 2012. ${ }^{4}$ Por hipótese, assume-se que a qualidade do ambiente institucional possui efeito positivo sobre os ingressos de IDE no Brasil e que a heterogeneidade institucional atua no sentido de elevar os custos de transação, limitando a entrada deste capital no mercado nacional.

O presente estudo justifica-se e torna-se importante para o fornecimento de informações mais precisas aos agentes econômicos envolvidos, ampliando e difundindo o debate sobre o ambiente institucional no Brasil. Este trabalho diferencia-se dos demais estudos

3 Os países de origem do IDE considerados são apresentados no modelo analítico, na quarta seção deste artigo.

4 A escolha do período levou em consideração a elevada entrada de IDE no mercado brasileiro, principalmente, a partir do programa de privatizações do governo Fernando Henrique Cardoso (FHC) em 1996, além da disponibilidade de dados das variáveis institucionais. 
da área ao propor uma investigação para um país receptor específico (Brasil), considerando o valor do IDE proveniente de uma ampla amostra de países de origem. Este estudo também se diferencia ao analisar a heterogeneidade institucional e realizar uma análise mais abrangente do ambiente institucional, visto que os indicadores institucionais utilizados englobam tanto aspectos político-sociais quanto econômico-financeiros.

O artigo está estruturado em outras cinco seções, além desta introdução: a segunda seção apresenta uma discussão teórica que fundamenta a pesquisa; a terceira aborda algumas evidências empíricas sobre os determinantes institucionais do IDE; a quarta descreve a metodologia de estimação do modelo gravitacional aplicado ao estudo dos fatores determinantes do IDE e indica a fonte dos dados utilizados; a quinta expõe e discute os resultados encontrados; e, por fim, a última seção traz as considerações finais do trabalho.

\section{Contribuições teóricas sobre IDE e os aspectos institucionais}

De acordo com a abordagem do Fundo Monetário Internacional FMI (2008), o IDE é uma categoria de investimento que visa adquirir um interesse duradouro em uma empresa localizada em outro país que não o do investidor, a fim de que este último possa exercer forte influência na gestão desta empresa. Ademais, o IDE pode ocorrer de dois modos: por meio de aquisições, quando uma empresa adquire outra firma estrangeira, ou por meio do investimento greenfield, quando uma firma cria uma nova subsidiária no exterior (FMI, 2008).

As empresas transnacionais (EMNs) são consideradas os principais agentes de promoção do IDE; logo, é de grande relevância entender as motivações que as levam a realizá-lo. Em conformidade com Nonnenberg e Mendonça (2005), dentre as teorias que trataram do processo de internacionalização ao longo das últimas décadas, especialmente no que diz respeito ao surgimento das EMNs e à análise dos determinantes do IDE, destacam-se as seguintes: teoria do ciclo do produto (Vernon, 1966); teoria da internacionalização da produção (Hymer, 1976); teoria da internalização dos custos de transação 
(Buckley e Casson, 1976); modelo de Uppsala (Johanson e Vahlne, 1994), e o paradigma eclético de Dunning (1993 e 2002).

Dentre as teorias citadas, a abordagem de Dunning (1993 e 2002) destaca-se por sua formulação mais abrangente e integrada ${ }^{5}$ do fenômeno da internacionalização da produção e dos diversos condicionantes do IDE, portanto, neste estudo, a teoria eclética foi utilizada para dar embasamento teórico às variáveis utilizadas como determinantes do fluxo de IDE. Este modelo de análise dos determinantes da atividade das EMNs baseia-se na justaposição de três fatores: as "vantagens de propriedade" privilegiada de alguns ativos, tangíveis ou intangíveis, como o poder de mercado, as habilidades empresariais e o marketing; as "vantagens de internalização" de determinados ativos - ao invés da venda, a empresa geraria valor com a internalização; e as "vantagens de localização" que as firmas asseguram ao direcionar sua produção para um determinado país, tais como vantagens relacionadas às legislações e às políticas governamentais, às estruturas de mercado e ao ambiente institucional, político, jurídico e cultural (Dunning, 1993 e 2002).

Deve-se salientar que as vantagens relativas à propriedade são classificadas entre as vantagens específicas da firma, enquanto que as vantagens de localização são designadas como específicas do país receptor do IDE. Deste modo, diante do enfoque integrado da ação das EMNs, Dunning (1993) propôs a classificação do IDE conforme quatro principais tipos de projetos: market seeking (busca de mercado), resource seeking (busca de recursos), efficiency seeking (busca de eficiência) e asset seeking (busca de ativos estratégicos, ou seja, compra de firmas existentes). Ainda segundo Dunning (1993 e 2002), é importante ressaltar as diferenças existentes entre os fluxos de IDE apenas entre países desenvolvidos (origem e receptores) e os fluxos em que os receptores são países em desenvolvimento. Enquanto no primeiro caso ocorrem investimentos do tipo procura de ativos estra-

5 De acordo com Fernandes (2006), o paradigma eclético de Dunning (1993 e 2002) apresenta-se como uma teoria mais completa e eclética, como o próprio nome diz, pois tenta reunir numa mesma abordagem teórica os aspectos sobre a internalização dos custos de transação que foram inicialmente explorados por Buckley e Casson (1976) e são tratados por Dunning como as "vantagens de internalização" - as vantagens específicas desenvolvidas pela firma - investigadas pela teoria da internacionalização da produção de Hymer (1976) e tratadas no modelo de Dunning como as "vantagens de propriedade" - e, por fim, as características locacionais de mercados específicos - exploradas na teoria do ciclo do produto de Vernon (1966), no Modelo de Uppsala de Johanson e Vahlne (1994) e abordadas no o paradigma eclético de Dunning como as "vantagens locacionais" de determinado mercado. 
tégicos e de eficiência horizontal, no segundo o IDE é caracterizado pela procura de mercados, recursos ou eficiência vertical.

Ademais, Dunning e Lundan (2008) reconheceram que os movimentos contemporâneos estão levando os pesquisadores em negócios internacionais a dar maior atenção à abordagem institucional. Diante desse cenário, Dunning e Lundan (2008), em suas considerações sobre o Paradigma Eclético, passaram a valorizar a importância das instituições na determinação do IDE, levando em conta que quando uma empresa decide investir em outro país, avalia, ceteris paribus, os aspectos institucionais envolvidos. Com isso, os autores acrescentaram uma vertente institucional aos três pilares do Paradigma Eclético, posicionando as vantagens de propriedade, de localização e de internalização no contexto de instituições formais e informais que influenciariam os processos de agregação de valor.

O emprego dos aspectos institucionais na economia ganhou força a partir dos trabalhos de Douglass North e Oliver Williamson, que se tornaram os maiores expoentes da Nova Economia Institucional (NEI) (North, 1990; Williamson, 2000). Em sua obra seminal de 1990, intitulada Institutions, Institutional Change and Economic Performance, North investiga a dinâmica institucional da sociedade, analisando aspectos como incerteza, custos de transação e organizações. Desse modo, a NEI advoga que as instituições e a melhoria do ambiente institucional dos países trazem três importantes contribuições para o bom funcionamento dos mercados e dos investimentos: reduzem os custos de transação, ao melhorar a qualidade das informações; protegem os direitos de propriedade; e balizam o ambiente de competição, ao impor regras.

Mudambi e Navarra (2002) ressaltaram que as estruturas institucionais dos países eram consideradas um fator de importância secundária, privilegiando-se o ambiente administrativo e indicadores técnicos. No entanto, os autores destacaram que, na realidade, os mercados funcionam com imperfeições e, nesse contexto, as instituições seriam cruciais para resolver eventuais falhas. Logo, a teoria de negócios internacionais deveria considerar o ambiente institucional como uma vantagem locacional, constituindo-se em um elemento fundamental na explicação dos fluxos de investimentos externos, uma vez que a melhoria dos aspectos institucionais teria possíveis efeitos positivos sobre o IDE. 
Adicionalmente, conforme Berry et al. (2010), os estudos ${ }^{6}$ dos impactos institucionais sobre a atuação das EMNs estão intimamente relacionados às pesquisas referentes à distância (heterogeneidade) transnacional. Estes trabalhos defendem que os países são distantes uns dos outros, não só pela distância geográfica, que eleva custos de transações, mas também porque diferenças econômicas, sociais, culturais ou políticas aumentam as incertezas e dificuldades para as empresas operarem além de suas fronteiras nacionais.

Autores como Peng et al. (2009), Berry et al. (2010) entre outros, visando contribuir com a pesquisa referente às heterogeneidades transnacionais, elaboraram um conjunto de medidas multidimensionais baseadas na NEI e nas teorias do IDE. Em síntese, essas medidas compreendem: distância cultural - diferenças de idiomas, religiões, raças, normas e valores sociais; distância geográfica - distância física, tamanho do país-anfitrião; distância institucional - heranças coloniais, sistemas políticos, instituições; e distância econômica disponibilidade de recursos naturais, financeiros, poder aquisitivo, infraestrutura, acesso a insumos e conhecimentos. De modo geral, os autores avaliam que a elevação dessas medidas entre os países de origem e destino do IDE aumentam as incertezas, riscos, custos de transação e implantação, o que acaba por impactar negativamente os investimentos.

\section{Evidências empíricas sobre os determinantes institucionais do IDE}

As evidências empíricas dos estudos que têm analisado as relações entre os fluxos de investimento direto estrangeiro e seus principais determinantes demonstram que é crescente a preocupação por parte dos pesquisadores em relação à análise da influência de fatores institucionais sobre o IDE. Além disso, estes trabalhos apontam a atenção que os governos devem ter em relação à criação de um bom ambiente de investimento.

${ }^{6}$ Como exemplo, tem-se: Kogut e Singh (1988), Kostova (1996), Larimo (2003) e Peng et al. (2009). 
Trabalhos como os de Wei (2000), Globerman e Shapiro (2002) e Daude e Stein (2007), influenciados pela abordagem dos aspectos institucionais, buscaram avaliar o impacto destes fatores sobre a entrada de IDE em diferentes conjuntos de países. Para Daude e Stein (2007), que analisaram os determinantes do fluxo de investimento direto estrangeiro em um painel de dados formado por 34 países de origem e 152 países destino, ficou evidente que a qualidade institucional é um fator estatisticamente significante e positivo para atrair investimento direto externo. Wei (2000), usando dados bilaterais dos estoques de IDE dos países da Organização para a Cooperação e Desenvolvimento Econômico (OCDE), mostrou que a corrupção e a incerteza gerada afetaram negativamente a localização do investimento estrangeiro. No caso do estudo de Globerman e Shapiro (2002), com uma amostra de 144 países entre desenvolvidos e em desenvolvimento, os autores confirmam que boa governança e um regime legal transparente são variáveis importantes para atração e realização de IDE. Outro estudo relevante foi o trabalho de Del Bo (2009), a autora investigou os efeitos da instabilidade cambial e institucional sobre os fluxos de IDE entre países desenvolvidos e emergentes, os resultados encontrados foram que tanto a variabilidade da taxa de câmbio quanto o risco político tiveram um efeito negativo sobre os fluxos deste investimento.

Segundo Bevan et al. (2004), os aspectos institucionais são fatores preponderantes para determinar se um país é atrativo ou não para o IDE. Entretanto, ainda não há consenso sobre quais instituições realmente importam. Para avaliar estes fatores institucionais, Campos e Kinoshita (2003) e Bevan et al. (2004) analisaram países do leste europeu, os quais tiverem um período de transição de uma economia socialista para uma economia capitalista. Os resultados encontrados nestes trabalhos apontam que variáveis como direito de propriedade privada, reforma do setor bancário, integração regional e liberalização comercial foram capazes de influenciar positivamente a entrada de IDE nos países investigados.

Amal e Seabra (2007) examinaram os determinantes do investimento direto estrangeiro na América Latina, com ênfase no impacto das variáveis institucionais sobre a decisão de investir das empresas multinacionais. Utilizando um modelo de dados em painel para o conjunto de países da América Latina, os resultados encontrados pelos autores indicam que, na perspectiva da busca de mercados 
locais ou regionais, os fatores institucionais - como grau de liberdade econômica e risco político - são estatisticamente significantes para explicar a atração do IDE. Seguindo nesta linha de estudos com amostras regionalizadas, outros trabalhos importantes que investigaram os determinantes institucionais dos fluxos de IDE na América Latina e Caribe foram os trabalhos de Dias (2014), Blanco (2012), Ramirez (2010) e Bengoa e Sanchez-Robles (2003).

Em relação aos estudos dos efeitos da heterogeneidade institucional entre países de origem e destino dos fluxos de investimento direto estrangeiro, destacam-se os trabalhos de Bénassy-Quéré et al. (2007) e Habib e Zurawicki (2002). Bénassy-Quéré et al. (2007) estimaram uma equação gravitacional para o conjunto de países da OCDE, considerando tanto os aspectos institucionais dos países receptores do IDE quanto a distância institucional entre os países de origem e de destino. Com base nos resultados obtidos, os autores concluíram que boas estruturas de governança podem atrair investidores externos e que a heterogeneidade institucional pode reduzir os fluxos de IDE entre os países da amostra.

Habib e Zurawicki (2002) analisaram o impacto da distância institucional sobre os fluxos bilaterais de IDE para uma ampla amostra de países, porém não incluindo o Brasil. Concentrando-se nos aspectos relativos à corrupção, os autores encontraram que a diferença absoluta do índice de corrupção entre o país investidor e o país hospedeiro tem um impacto negativo sobre o IDE bilateral. Outros trabalhos que avaliaram questões relativas à heterogeneidade institucional foram: Aizenman e Spiegel (2002), Cuervo-Cazurra e Genc (2008) e Claessens e Van Horen (2008).

Ademais, Xu e Shenkar (2002) e Arslan e Larimo (2010) destacam que quanto maior o distanciamento institucional, cultural e geográfico entre o país de origem da empresa multinacional investidora e o país de destino do IDE, maiores podem ser os custos relacionados à transferência de tecnologia e de práticas gerenciais. Deste modo, as multinacionais estrangeiras sinalizam a preferência por estabelecimento do investimento direto externo em países que apresentem menor heterogeneidade institucional.

Diante do exposto, os esforços realizados para tratar as relações existentes entre a qualidade institucional e os fluxos de investimento 
estrangeiro, tanto do ponto de vista teórico quanto empírico, deixam clara a relevância do tema. Por outro lado, a escassez de verificações empíricas em relação a um conjunto de investidores externos (países de origem do IDE) e um país emergente receptor específico, aliada à constatação de que as instituições e as variáveis macroeconômicas possuem efeito diferenciado sobre cada mercado, abrem espaço para esforços nesse sentido, focando o estudo em relação à economia brasileira.

\section{Metodologia}

\subsection{Modelo analítico}

Embora tradicionalmente desenvolvidos para explicar fluxos bilaterais de comércio, os modelos gravitacionais ${ }^{7}$ têm sido estimados para fluxos de investimentos estrangeiros, com o argumento de que as variáveis tradicionais desta abordagem, como distância e tamanho do PIB dos países, são significativas para explicar as decisões de investir das empresas multinacionais. Ademais, a justificativa teórica para a utilização do modelo gravitacional remonta ao paradigma eclético de Dunning (1993), que mostra a influência do tamanho do mercado e das vantagens de localização sobre o fluxo de IDE.

O modelo gravitacional básico para o comércio (ou IDE) pode ser representado na forma logarítmica como: $\ln \left(T_{i j, t}\right)=\beta_{0}+\beta_{1} \ln \left(Y_{i, t} Y_{j, t}\right)-\beta_{2} \ln \left(\right.$ Dist $\left._{i j}\right)+\mu_{i j, t}$. De acordo com essa modelagem, o fluxo de comércio (ou IDE) entre os países i e j $\left(T_{i j}\right)$ é uma função crescente do produto de suas rendas $\left(Y_{i} Y_{j}\right)$, utilizadas como proxies para o tamanho do mercado em cada país e medidas pelo PIB, e decrescente em relação à distância (Dist $\left.{ }_{i j}\right)$ entre eles, geralmente interpretada como proxy dos custos de transação (Africano; Magalhães, 2005).

Portanto, para o período de 1996 a 2012, este estudo realiza a estimação da equação gravitacional básica com a inclusão de indicadores representativos da qualidade e heterogeneidade institucional, expressando algumas das variáveis representativas dos custos de transação

Para mais detalhes sobre esta modelagem e estudos relacionados, ver Anderson e Van Wincoop (2004), Wei (2000), Daude e Stein (2007), Bénassy-Quéré et al. (2007) e Del Bo (2009). 
não observados, indicadas por Anderson e Van Wincoop (2004). Ademais, foi considerada a estimação do modelo com efeitos fixos, permitindo a inclusão dos termos de resistência multilateral como fatores não observados na equação. Isso posto, os dados do ingresso de IDE na economia brasileira, proveniente dos 31 principais parceiros, ${ }^{8}$ foram estimados por meio de um modelo gravitacional com dados em painel, ${ }^{9}$ conforme a equação:

$$
\begin{aligned}
& \ln \left(I D E_{i j, t}\right)=\beta_{0}+\beta_{1} \ln \left(y_{i, t} y_{j, t}\right)+\beta_{2} \ln \left(\text { dist }_{i j}\right)+\beta_{3} \ln \left(A I E F_{i j, t}\right)+ \\
& \beta_{4} \ln \left(A I P S_{i j, t}\right)+\beta_{5} H I E F_{i j, t}+\beta_{6} H I P S_{i j, t}+\varepsilon_{i j, t}
\end{aligned}
$$

em que $I D E_{i j, t}$ representa os fluxos de IDE do país de origem $j$ para o país de destino $i$ (ou seja, o Brasil), no ano $t ; y_{i, t} y_{j, t}$ é o produto das rendas (PIB's) dos países i e j, no período t (proxy para tamanho do mercado); dist $t_{i j}$ é a distância geográfica ${ }^{10}$ entre os países i e j; $A I E F_{i j, t}$ representa o indicador do ambiente institucional econômicofinanceiro entre o Brasil e cada país de origem do investimento $\mathrm{j}$, no período t; $A I P S_{i j, t}$ representa o indicador do ambiente institucional político-social entre o Brasil e cada país de origem do investimento $\mathrm{j}$, no ano t; $H I E F_{i j, t}$ representa a heterogeneidade institucional calculada com base nos indicadores da qualidade institucional econômicofinanceira (IEF) do Brasil e de cada parceiro j, no período t; $H I P S_{i j, t}$ representa a heterogeneidade institucional calculada com base nos indicadores da qualidade institucional político-social (IPS) do Brasil e de cada parceiro j, no ano t; e $\varepsilon_{i j, t}$, o termo de erro aleatório. $O \ln$ representa as variáveis que foram logaritmizadas.

Como verificado na equação anterior, para representar a qualidade do ambiente institucional dos países, foi realizada a construção de um indicador englobando os aspectos institucionais político-sociais e outro indicador compreendendo os aspectos institucionais econômico-financeiros. As variáveis utilizadas na elaboração do índi-

8 Os países incluídos na amostra representam mais de 92\% do ingresso de IDE no Brasil, são eles: Estados Unidos, Países Baixos, Luxemburgo, Suíça, Espanha, França, Chile, Reino Unido, Canadá, Japão, Cingapura, Itália, Noruega, Alemanha, Bélgica, Uruguai, Portugal, Austrália, Hong Kong, Dinamarca, Suécia, Irlanda, México, Argentina, Panamá, China, Colômbia, Bahamas, Peru, Áustria e Finlândia.

9 Para mais informações sobre o modelo de dados em painel, seus testes de hipóteses pertinentes e os comandos para estimação pelo software STATA, ver Cameron e Trivedi (2009), capítulo 8.

${ }^{10}$ É a distância em quilômetros entre a cidade mais populosa do Brasil, São Paulo, e a cidade mais populosa de cada parceiro considerado na análise. 
ce representativo da qualidade institucional político-social serão as mesmas propostas por Kaufmann et al. (2009) e referem-se a seis dimensões: ${ }^{11}$ nível de democracia, estabilidade política, efetividade das políticas governamentais, qualidade regulatória, cumprimento da Lei, e controle da corrupção. Já em relação às variáveis utilizadas na elaboração do indicador representativo da qualidade institucional econômico-financeira, foram considerados os seguintes índices disponibilizados no banco de dados da Heritage Foundation ${ }^{12}$ (2014): liberdade de negócios, liberdade comercial, liberdade fiscal, liberdade monetária, liberdade financeira, e liberdade de investimentos.

O índice da qualidade institucional político-social (IPS) e o índice da qualidade institucional econômico-financeiro (IEF) foram mensurados por meio da média das respectivas variáveis para cada país, em cada ano do período de 1996 a 2012. Obtidos estes indicadores, a medida do ambiente institucional político-social (AIPS) e do ambiente institucional econômico-financeiro (AIEF) entre o Brasil e cada país de origem do IDE foi calculada por meio da multiplicação (interação) dos indicadores IPS e IEF do Brasil e de cada parceiro investidor, em cada ano. A motivação para este procedimento é que as variáveis institucionais propostas por Kaufmann et al. (2009) são altamente correlacionadas, o que inviabiliza a inclusão de cada medida específica em um mesmo modelo econométrico sem incorrer em problemas de multicolinearidade. Portanto, pode-se dizer que os indicadores do ambiente institucional sugerem que, quanto melhor a qualidade institucional do Brasil e de determinado país investidor, menores serão as restrições para o investimento e maiores serão as probabilidades de ingresso de IDE na economia brasileira. Em seguida, para medir a heterogeneidade institucional, foi utilizado o procedimento proposto por Linders (2006). Este procedimento compreende a elaboração de uma variável contínua para mensurar a distância

${ }^{11}$ Essas variáveis são resultado de um amplo esforço de pesquisa no âmbito do projeto Worldwide Governance Indicators (WGI) do World Bank. O WGI é composto por estes seis indicadores agregados que representam amplas dimensões de governança, englobando informações de cerca de 200 países, desde 1996. Estes indicadores institucionais e mais informações podem ser obtidos no site do Banco Mundial ou no site do projeto (www.govindicators.org). Os índices variam entre $-2,5$ e 2,5, sendo que valores mais elevados estão associados à maior qualidade institucional.

$12 \mathrm{O}$ conjunto de dados fornecido por esta instituição engloba diferentes variáveis que caracterizam a liberdade de atuação econômica e financeira em determinado país. Cada categoria considerada é classificada em uma escala de 0 a 100, sendo a pontuação geral de um país derivada pela média de pontuação das categorias consideradas, com peso igual para cada categoria. Mais informações sobre a classificação e a metodologia de cálculo desses índices podem ser encontradas no seguinte link: www.heritage.org/index/about. 
institucional entre os países da amostra. Assim, a heterogeneidade institucional político-social (HIPS) e econômico-financeira (HIEF) entre o Brasil e cada país da amostra foi calculada da seguinte forma:

$$
H I_{i j, t}=\left(I_{s i, t}-I_{s j, t}\right)^{2} / V_{s}
$$

em que $I_{s i . t}$ representa o valor do índice da qualidade institucional $s$ (IEF ou IPS) para o país receptor do IDE $i$ (neste caso o Brasil), no ano $t ; I_{s j, t}$ representa o valor do índice da qualidade institucional $s$ para o país de origem do IDE $j$, no ano t; e $V_{s}$ a variância do índice $s$ na amostra.

\subsection{Métodos de estimação}

A escolha do método de estimação é de grande relevância para a mensuração dos efeitos das variáveis analisadas nos estudos sobre os fluxos de IDE e de comércio. Nesse sentido, conforme Anderson e Van Wincoop (2004), a estimação de uma equação gravitacional pode ser realizada por meio de um modelo de efeitos fixos por Mínimos Quadrados Ordinários (MQO), utilizando-se variáveis dummies específicas por países e tempo para representar os termos de resistência multilateral.

De acordo com Greene (2008), a presença de fatores não observados, neste caso os termos de resistência multilateral, correlacionados com as demais variáveis explicativas, aponta a estimação por efeitos fixos como a mais adequada, pois a estimação do modelo de efeitos fixos permite a inclusão dos termos de resistência multilateral como fatores não observados na equação empírica, o que evita o viés causado pela omissão dessas variáveis, que, de outro modo, estariam expressas no termo de erro da equação. Portanto, o problema que ocorre quando esses termos são omitidos está relacionado à sua correlação com as proxies adicionadas no modelo como forma de representar os custos de transação não observados.

A definição da especificação dos efeitos fixos está condicionada aos objetivos de cada trabalho. Visto que o objetivo do presente estudo é mensurar os impactos enfrentados pela entrada de IDE na economia 
brasileira, ou seja, medir o efeito de variáveis construídas com informações relacionadas a pares de países, torna-se mais indicado o uso de dummies por país e tempo. No entanto, em conformidade com Mendonça et al. (2011) e dado que a estimação do modelo é realizada apenas para o Brasil como país receptor $i$ do IDE, as dummies por país de origem $j$ atuariam como dummies para pares de países, o que poderia causar a captura do efeito dos indicadores institucionais sobre os fluxos de IDE. Logo, neste trabalho, as estimações da equação gravitacional empírica (1) foram realizadas utilizando-se apenas os efeitos fixos de tempo.

Outros aspectos importantes na estimação do modelo gravitacional referem-se à presença de fluxos internacionais discrepantes, em razão da grande heterogeneidade dos padrões de IDE entre países, e à presença de fluxos nulos em determinados períodos. Santos Silva e Tenreyro (2006) destacaram que uma forma conveniente de contornar o problema da heterocedasticidade, além de incluir os fluxos zero na amostra, seria a estimação pelo modelo não linear Poisson Pseudo-Maximum-Likelihood (PPML).

Portanto, conforme propõem Anderson e Van Wincoop (2004) e Santos Silva e Tenreyro (2006), para avaliar os impactos das diferentes variáveis do modelo adotado para análise do ingresso de IDE no Brasil, foram utilizados o modelo de efeitos fixos por MQO e o método PPML ${ }^{13}$ de Santos Silva e Tenreyro, também com efeitos fixos. A utilização destes dois estimadores dá-se pela coerência dos sinais e pelos indicadores de significância estatística dos coeficientes, permitindo uma análise complementar entre os métodos.

\subsection{Fonte dos dados}

Os dados relativos às séries do ingresso de investimento direto estrangeiro no Brasil (participação no capital) com distribuição por país de origem foram obtidos junto à base de dados do Banco Central do Brasil (BCB, 2013). Os indicadores institucionais econômico-fi-

\footnotetext{
${ }^{13}$ Mais informações sobre a estimação pelo método PPML, sua performance, seus comandos para estimação no STATA, entre outras características e particularidades do modelo podem ser encontradas no site dos autores (Santos Silva e Tenreyro) por meio do seguinte link: $<$ privatewww.essex.ac.uk/ jmcss/LGW.html>.
} 
nanceiros foram coletados por meio da base de dados disponibilizada pela Heritage Foundation e os indicadores institucionais políticosociais foram encontrados na base de dados do projeto Worldwide Governance Indicators (WGI) disponível no site do Banco Mundial. Em relação aos dados do PIB, estes foram obtidos junto às estatísticas econômicas também disponibilizadas no banco de dados do Banco Mundial. Já a variável distância referiu-se à distância em quilômetros entre as cidades mais populosas para cada par de países; esta variável foi obtida por meio dos dados do Centre D'Estudes Prospectives et d'Informations Internationales (CEPII, 2013). Quanto à unidade de mensuração, os dados dos PIB's e do IDE estão expressos em milhões dólares norte-americanos correntes. ${ }^{14}$

\section{Resultados e discussão}

\subsection{Análise descritiva dos dados}

As estatísticas descritivas gerais das variáveis que foram utilizadas na estimação do modelo empírico são apresentadas na Tabela 3. Os valores relativos às estatísticas descritivas da variável dependente, entrada de investimento externo na economia brasileira proveniente de cada um dos 31 parceiros em análise, evidenciam o caráter heterogêneo do fluxo de IDE para o Brasil. Observam-se tanto a presença de fluxos nulos, que correspondem ao não investimento no mercado brasileiro por alguns países como China, Peru e Dinamarca, entre os anos de 1996 e 1999, como também um elevado valor máximo, superior a US\$ 17 bilhões, correspondente ao IDE dos Países Baixos destinado ao Brasil, no ano de 2011.

Em relação ao tamanho do mercado entre o Brasil e determinado parceiro $\mathrm{j}$, ou seja, a variável $\mathrm{PIB}_{\mathrm{i}, \mathrm{t}} \mathrm{PIB}_{\mathrm{j}, \mathrm{t}}$, esta também mostrou-se heterogênea, revelando que o Brasil recebe investimentos externos provenientes tanto de economias com elevado PIB quanto de mercados com produto interno bruto relativamente menores. Quanto à variável distância (Dist $\mathrm{ij}_{\mathrm{j}, \mathrm{t}}$ ), é importante destacar que foi utilizada

${ }^{14}$ De acordo com Shepherd (2008), partindo do pressuposto que os custos de transação, despesas e rendimentos modificam-se ao longo do tempo, os termos de resistência multilaterais também se alteram com o tempo. Portanto, uma vez que estes termos já se assemelham aos índices de preços, não há nenhuma razão para qualquer deflator adicional.

Estud. Econ., São Paulo, vol. 46, n.2, p. 281-310, abr.-jun. 2016 
a distância em quilômetros entre a cidade mais populosa do Brasil, São Paulo, e a cidade mais populosa de cada parceiro considerado na análise. A distância média entre o Brasil e seus parceiros investidores ficou em torno de 9.296,25 km. O que equivale, aproximadamente, à distancia entre São Paulo e a capital dos Países Baixos, Amsterdã.

Tabela 3 - Médias, desvios-padrão e valores máximo e mínimo das variáveis que caracterizam a amostra utilizada na pesquisa, período 1996-2012

\begin{tabular}{|c|c|c|c|c|}
\hline Variáveis & Média & Desvio Padrão & Mínimo & Máximo \\
\hline $\mathrm{IDE}_{\mathrm{i}, \mathrm{t}}$ & 867,89 & $1.830,77$ & 0,00 & $17.581,99$ \\
\hline $\mathrm{PIB}_{i, t} \mathrm{PIB}_{\mathrm{j}, \mathrm{t}}$ & $1.073 .638,00$ & $2.214 .371,00$ & $4.232,89$ & $16.200 .000,00$ \\
\hline Dist $_{i j}$ & $9.296,25$ & $4.260,70$ & $1.567,88$ & $18.549,61$ \\
\hline $\mathrm{AlEF}_{\mathrm{i}, \mathrm{t}}$ & $4.494,47$ & 637,12 & $2.378,24$ & $6.094,18$ \\
\hline AIPS $_{i, t}$ & 0,01 & 0,01 & 0,00 & 0,05 \\
\hline $\mathrm{HIEF}_{\mathrm{i}, \mathrm{t}}$ & 3,76 & 4,06 & 0,00 & 31,96 \\
\hline $\mathrm{HIPS}_{\mathrm{i}, t}$ & 2,87 & 1,71 & 0,02 & 6,62 \\
\hline
\end{tabular}

Fonte: Dados da pesquisa.

Legenda: IDEij,t são os fluxos de IDE de cada país de origem j para o Brasil; PIBi,tPIBj,t é o produto das rendas (PIB's) dos países i e j (ou seja, tamanho do mercado); Distij é a distância entre os países i e j; AIEFij,t representa o indicador do ambiente institucional econômico-financeiro entre o Brasil e cada país de origem do investimento j; AIPSij,t representa o indicador do ambiente institucional político-social entre o Brasil e cada país de origem do investimento j; HIEFij,t representa a heterogeneidade institucional calculada com base nos indicadores da qualidade institucional econômico-financeira (IEF) do Brasil e de cada parceiro j; HIPSij,t representa a heterogeneidade institucional calculada com base nos indicadores da qualidade institucional político-social (IPS) do Brasil e de cada parceiro $j$.

Em relação aos indicadores representativos do ambiente institucional econômico-financeiro $\left(\mathrm{AIEF}_{\mathrm{ij}, \mathrm{t}}\right)$ e político-social $\left(\mathrm{AIPS}_{\mathrm{ij}, \mathrm{t}}\right)$ e das heterogeneidades institucionais $\left(\mathrm{HIEF}_{\mathrm{ij}, \mathrm{t}}\right.$ e HIPS $\left._{\mathrm{ij}, \mathrm{t}}\right)$ expressos na Tabela 3, é importante observar os valores máximo e mínimo de cada índice, pois, para os indicadores do ambiente institucional, quanto maior forem os valores destes, seja político-social ou econômico financeiro, melhor será a qualidade das instituições envolvendo o Brasil e determinado país investidor. Por outro lado, para os indicadores da heterogeneidade institucional, quanto maior forem os valores destes, maiores serão as dissimilaridades institucionais entre o Brasil e determinado país de origem do IDE. Valores elevados para este indicador significam que o Brasil apresenta uma qualidade institucional superior à do seu parceiro ou apresenta aspectos institucionais político-sociais ou econômico-financeiros bem inferiores. 


\subsection{Impactos da qualidade institucional e sua heterogeneidade sobre o ingresso de IDE na economia brasileira}

Os resultados apresentados na Tabela 4 baseiam-se na estimação dos coeficientes da equação gravitacional empírica (1) por meio do modelo de Efeitos Fixos (EF) estimado por MQO e na estimação utilizando o método PPML, também com EF. A utilização destes estimadores permite a comparação dos resultados entre os modelos.

A adequação e a robustez dos resultados foram aferidas por diferentes estatísticas. A significância dos coeficientes do modelo de efeitos fixos estimado por MQO foi examinada por meio do Teste $\mathrm{F}$ de Chow. O Teste de Wald foi empregado para verificar a significância conjunta das variáveis na estimação em que o método PPML foi utilizado. Adicionalmente, é importante destacar que a escolha do modelo de efeitos fixos, em relação ao de efeitos aleatórios, pôde ser confirmada por meio do teste de Hausman. Pode-se dizer que não é possível rejeitar a hipótese nula de que efeitos de heterogeneidades não observáveis dos países afetam o fluxo de investimento externo para o Brasil. O modelo com EF de tempo e a inclusão das variáveis institucionais para captar as dissimilaridades não observáveis dos países é preferível, uma vez que o mesmo leva em consideração as peculiaridades dos países.

$\mathrm{Na}$ Tabela 4, os valores relativos ao ingresso de IDE na economia brasileira, provenientes dos 31 principais países de origem considerados no estudo, constituem a variável dependente no período entre 1996 e 2012. De maneira geral, os resultados obtidos a partir das estimações por MQO e PPML foram bons, com a maioria dos coeficientes estimados apresentando significância estatística e mostrando-se similares em termos de magnitude e sinais esperados para todas as variáveis explicativas observadas. Além disso, por meio do Teste F e Teste Wald, a hipótese de que todos os coeficientes não explicam o ingresso de IDE no mercado brasileiro foi rejeitada a $1 \%$ de significância, ou seja, pode-se afirmar que, conjuntamente, as variáveis são estatisticamente significantes. 
Tabela 4 - Estimativas MQO e PPML, com Efeitos Fixos, da equação gravitacional (1) para o ingresso de investimento direto estrangeiro na economia brasileira, 1996 - 2012

\begin{tabular}{|c|c|c|c|c|c|c|}
\hline \multirow[b]{2}{*}{ Variáveis } & \multicolumn{3}{|c|}{ PPML Efeitos Fixos } & \multicolumn{3}{|c|}{ MQO Efeitos Fixos } \\
\hline & Coeficiente & $\begin{array}{l}\text { Erro Padrão } \\
\text { Robusto }\end{array}$ & P-valor & Coeficiente & $\begin{array}{l}\text { Erro Padrão } \\
\text { Robusto }\end{array}$ & P-valor \\
\hline $\ln \mathrm{PIB}_{\mathrm{i}, \mathrm{P}} \mathrm{PIB}_{\mathrm{j}, \mathrm{t}}$ & $0,441^{\star \star \star}$ & 0,047 & 0,000 & $0,498^{\star \star \star}$ & 0,047 & 0,000 \\
\hline InDist $_{\text {ij }}$ & $-0,470^{\star \star \star}$ & 0,108 & 0,000 & $-0,449^{\star \star \star}$ & 0,174 & 0,010 \\
\hline $\operatorname{InAIEF} F_{i, t}$ & $6,044^{* * *}$ & 1,274 & 0,000 & $6,373^{\star * *}$ & 0,936 & 0,000 \\
\hline $\operatorname{lnAIPS} S_{i, t}$ & $0,448^{* * *}$ & 0,139 & 0,001 & $0,180^{*}$ & 0,105 & 0,087 \\
\hline $\mathrm{HIEF}_{\mathrm{i}, \mathrm{t}}$ & $-0,147^{\star \star \star}$ & 0,039 & 0,000 & $-0,177^{\star \star \star}$ & 0,032 & 0,000 \\
\hline $\mathrm{HIPS}_{\mathrm{i}, \mathrm{t}}$ & $-0,071 \mathrm{~ns}$ & 0,104 & 0,496 & $-0,052 n s$ & 0,096 & 0,585 \\
\hline Constante & $-40,639^{\star \star \star}$ & 10,500 & 0,000 & $-46,189^{\star \star \star}$ & 7,783 & 0,000 \\
\hline $\mathrm{R}^{2}$ & 0,41 & & & 0,40 & & \\
\hline № observações & 526 & & & 492 & & \\
\hline Teste F & - & & & $12,97^{\star \star *}$ & & 0,000 \\
\hline Teste Wald & $270,76^{\star \star \star}$ & & 0,000 & - & & \\
\hline
\end{tabular}

Fonte: Resultados da Pesquisa.

Nota: Asterisco simples $\left({ }^{*}\right)$, duplo $\left({ }^{* *}\right)$ e triplo $\left({ }^{* * *}\right)$ denotam significância a $10 \%, 5 \%$ e $1 \%$, respectivamente, enquanto ns indica ausência de significância.

De acordo com os resultados apresentados na Tabela 4, para os dois métodos de estimação, todas as variáveis apresentaram os sinais esperados. Considerando um nível significância estatística de $1 \%$, verifica-se que apenas a variável representativa da heterogeneidade institucional político-social não revelou coeficientes estatisticamente significantes para os dois estimadores considerados ${ }^{15}$ e que a variável relativa ao indicador do AIPS obteve significância estatística de 1\% somente na estimação pelo método PPML.

No que tange à variável distância, o coeficiente encontrado foi estatisticamente significante a $1 \%$ e negativo, estando de acordo com o preconizado pela teoria e semelhante às relações encontradas em estudos como os de Del Bo (2009), Daude e Stein (2007), BénassyQuéré et al. (2007) e Dias (2014). Este resultado aponta que um aumento de $1 \%$ na distância geográfica (proxy para os custos de transação), considerando o coeficiente estimado pelo método PPML, por exemplo, reduziria em $0,47 \%$ o ingresso de IDE no mercado bra-

${ }^{15}$ Desse modo, no restante da discussão desta seção, quando determinada variável for citada e o método de estimação não for mencionado, deve-se considerar que a análise refere-se aos resultados dos dois estimadores utilizados, uma vez que os coeficientes estimados revelaram valores aproximados. 
sileiro. Logo, quanto maior a distância entre o Brasil e determinado país de origem, maiores seriam os custos de transação, informação e o desconhecimento sobre as particularidades do mercado nacional e menores poderiam ser os ingressos de investimentos.

Em relação à variável utilizada para mensurar o tamanho do mercado entre os países, neste caso o produto dos PIB's, esta revelou um efeito positivo e estatisticamente significante sobre o fluxo de IDE entrante na economia brasileira. Este resultado indica, por exemplo, que um aumento de $1 \%$ no nível de renda dos países (proxy para tamanho de mercado), considerando o coeficiente estimado por MQO, elevaria em $0,44 \%$ o ingresso de investimento direto estrangeiro no mercado brasileiro. Este seria o caso, por exemplo, da elevação do ingresso de IDE no Brasil gerado pelo crescimento na renda dos seus maiores parceiros investidores - como EUA, Suíça, Países Baixos, França, entre outros - e, ou, pelo crescimento do próprio mercado brasileiro, o que estimularia a entrada de IDE em busca desse mercado em expansão.

Na sequência, analisando os coeficientes estimados do logaritmo dos indicadores do ambiente institucional político-social e econômicofinanceiro (AIPS e AIEF), verifica-se que ambos apresentaram uma relação direta e estatisticamente significante com os fluxos de investimento externo destinado à economia brasileira. Este resultado demonstra que quanto melhor for o ambiente institucional entre os países e maior for a qualidade das instituições brasileiras, maiores serão os volumes de capital estrangeiro destinados ao Brasil. Nesse sentido, segundo o World Bank (2005), é crescente a preocupação por parte dos governos em relação à criação de um bom clima (ambiente) de investimento, onde muitos países estão criando instituições de apoio para auxiliar em tarefas específicas e sustentar os níveis de investimentos através de mudanças nas ações governamentais.

Adicionalmente, é interessante ressaltar que os resultados positivos e estatisticamente significantes dos coeficientes estimados dos indicadores do AIEF e AIPS, considerando a estimação pelo método PPML, apontam que um aumento de $1 \%$ no indicador da qualidade do AIEF e do AIPS elevaria o ingresso de investimento direto estrangeiro no mercado brasileiro, respectivamente, em $6,04 \%$ e $0,44 \%$. Portanto, estes resultados sugerem que os agentes econômicos que investem na economia brasileira buscam um ambiente de investimen- 
to com maior estabilidade jurídica e política, liberdade financeira, econômica e comercial, que possa assegurar-lhes maior transparência, segurança e credibilidade para os seus investimentos.

Em conformidade com estes aspectos, o trabalho de Chede (2008), que analisou os determinantes institucionais do investimento direto externo em direção a oito países em desenvolvimento, dentre eles o Brasil, encontrou resultados estatisticamente significantes que revelaram a grande importância e influência dos aspectos institucionais sobre a decisão de investimento em países emergentes. Neste sentido, outras pesquisas empíricas importantes foram os estudos de Blanco (2012), Mudambi e Navarra (2002), Ramirez (2010), Amal e Seabra (2007), Bengoa e Sanchez-Robles (2003) e Dias (2014). Estes trabalhos apresentam um ponto em comum, que é a análise dos determinantes dos fluxos de IDE na América Latina e Caribe, considerando o impacto de fatores institucionais sobre os investimentos estrangeiros destinados às economias desta região. Em síntese, os resultados encontrados pelos estudos indicam que o tamanho do mercado, a estabilidade econômica e os fatores institucionais, como grau de liberdade econômica, risco político e efetividade do governo, foram os mais relevantes para explicar a atração do IDE. Além disso, os autores destacam que este comportamento decorre do fato de que a melhoria na qualidade institucional contribui com a redução dos custos transacionais e com a formação de um ambiente de estabilidade jurídica e regulatória, tornando o mercado doméstico mais atraente, transparente e menos instável.

No caso dos coeficientes estimados para os indicadores representativos da heterogeneidade institucional econômico-financeira (HIEF) e político-social (HIPS), observa-se que as estimativas dos dois indicadores apresentaram o sinal negativo esperado, mas, por outro lado, apenas o indicador da HIEF revelou-se estatisticamente significante, ao nível de $1 \%$, tanto para o estimador de MQO quanto para o PPML (Tabela 4). Este resultado revela que os efeitos da heterogeneidade institucional político-social não foram estatisticamente significantes sobre os fluxos de IDE para o Brasil, indicando que o fluxo entrante de investimento direto externo não foi afetado pela dissimilaridade dos aspectos político-sociais considerados. Nesse sentido, Santos (2009), em seu estudo sobre os determinantes do investimento estrangeiro de portfólio de países europeus em países de destino da própria União Europeia e outros países da OCDE e mercados 
emergentes, encontrou resultado semelhante para a variável distância política, ou seja, a heterogeneidade de algumas características políticas e sociais não afetou os fluxos dos investimentos estrangeiros de portfólio destinados a países tanto desenvolvidos quanto emergentes.

Adicionalmente, outros estudos, como os de Asiedu (2006), UNCTAD (2007) e Robinson et al. (2006), atestam que boa parte do crescimento do IDE impulsionado pelo investimento na exploração de recursos naturais é destinada a países com baixa qualidade institucional e abundância destes recursos, mostrando que, em muitos casos, o IDE orientado pela estratégia de busca por recursos pode não sofrer efeitos restritivos significativos devido ao distanciamento de aspectos institucionais políticos e sociais entre o país investidor e o receptor. Este fato está diretamente ligado à teoria de Dunning (1993 e 2002), a qual ressalta que os fluxos de IDE destinados a países em desenvolvimento são caracterizados pela procura de recursos, mercados ou eficiência vertical. Diante deste aspecto e em conformidade com o relatório da CEPAL (2011), vale destacar que, no Brasil e em outros países da América Latina e Caribe, tem ocorrido um forte incremento dos investimentos externos na extração de hidrocarbonetos, minerais e outros recursos naturais, sendo essa busca por estes recursos, uma possível explicação para o impacto estatisticamente não significante da HIPS sobre o ingresso de IDE no mercado brasileiro.

Contudo, a disparidade institucional econômico-financeira entre o Brasil e os países de origem do IDE apresentou efeito restritivo estatisticamente significante sobre os fluxos deste capital, reforçando os resultados destacados anteriormente. Esses resultados sugerem que a diferença na qualidade das instituições financeiras e nos aspectos econômicos entre o Brasil e seus parceiros investidores reduzem os fluxos de IDE destinados ao mercado brasileiro. Portanto, a desigualdade entre o arranjo institucional financeiro da economia brasileira e dos países de origem do capital externo geram maiores custos de transação, ${ }^{16}$ afetando de forma negativa o volume de IDE recebido pelo Brasil.

16 Neste caso, os maiores custos de transação podem ser entendidos como elevados gastos com as operações financeiras, seguros, e intermediação de recursos, devido ao maior risco de se investir em uma economia com assimetria de informação e instituições econômico-financeiras menos desenvolvidas, além de custos maiores ocasionados pela ineficiência dos serviços, dos intermediários financeiros, e com possíveis gastos com meios legais para a solução de controvérsias, entre outros. 
Neste contexto, Bénassy-Quéré et al. (2007), utilizando dados de estoques bilaterais de IDE entre países da OCDE, encontraram resultados que evidenciaram impacto negativo da distância institucional sobre os fluxos de investimento direto estrangeiro, com destaque para a heterogeneidade na regulamentação do mercado de crédito, que revelou o maior impacto negativo dentre as variáveis relativas à distância institucional. Adicionalmente, Weeks (2014), ao analisar a influência do ambiente de negócios sobre a determinação dos fluxos bilaterais de IDE, destaca que o Brasil encontra-se em uma situação de menor desenvolvimento relativo, como, por exemplo, em relação à facilidade e eficiência em concretizar transações financeiras. Ainda segundo o autor, esta má classificação do ambiente de negócios brasileiro frente a outros países revela um grande potencial de melhora na atração do IDE, caso essa disparidade institucional seja reduzida.

Em síntese, os resultados obtidos pela pesquisa sugerem a existência de uma relação entre o ambiente institucional desenvolvido, ou de boa qualidade, e os custos de transação incorridos pelos agentes, conforme destacado pela teoria. Embora não tenha sido encontrado efeito direto da heterogeneidade institucional político-social sobre a entrada de capital estrangeiro no Brasil, os resultados indicaram que a existência de instituições e aspectos econômico-financeiros díspares entre o Brasil e seus principais parceiros limitou o fluxo de investimento externo entrante. Este fato mostra a importância e interesse dos investidores em mercados com maior liberdade econômica e facilidades para efetuar negociações financeiras.

\section{Conclusão}

Diante da evolução do ingresso de investimento direto estrangeiro na economia brasileira e da crescente preocupação com aspectos institucionais nos países receptores e de origem deste tipo de investimento, o presente estudo propôs-se a avaliar como a qualidade do ambiente institucional e sua heterogeneidade tem afetado a entrada de IDE no mercado brasileiro, no período de 1996 a 2012.

Os resultados obtidos por esta análise evidenciaram que o volume entrante de IDE no Brasil é positivamente afetado pela qualidade do ambiente institucional político-social e econômico-financeiro entre 
os países de origem e o Brasil. Além disso, a disparidade institucional econômico-financeira mostrou-se negativamente relacionada com o ingresso do capital externo. Desse modo, conclui-se que não se pode rejeitar a hipótese de que a qualidade do ambiente institucional possui efeito positivo sobre os ingressos de IDE no Brasil e que a heterogeneidade institucional econômico financeira atua no sentido de elevar os custos de transação, limitando a entrada deste capital no mercado brasileiro.

A relação positiva entre o ingresso de IDE na economia brasileira e a qualidade do ambiente institucional evidencia a importância de esforços por parte do Brasil no sentido de promover avanços nos aspectos institucionais que compõem os indicadores da qualidade do ambiente institucional político-social e econômico-financeiro. Este seria o caso de progressos na qualidade regulatória, controle da corrupção, cumprimento das leis, nível de democracia, efetividade das políticas governamentais, estabilidade política e maior liberdade econômico-financeira. Desta forma, estes avanços resultariam na redução dos custos, incertezas e riscos característicos de ambientes com baixa qualidade institucional, como no caso brasileiro, e, consequentemente, elevariam o ingresso de IDE na economia nacional.

Por fim, considerando que a maioria dos países de origem do investimento direto estrangeiro destinado ao Brasil refere-se a economias desenvolvidas, com instituições econômicas e financeiras consolidadas e avançadas, é importante salientar que o efeito negativo e estatisticamente significante da heterogeneidade institucional econômico-financeira requer maior atenção do governo e das instituições privadas brasileiras no intuito de gerar melhorias que diminuam esta distância institucional, criando maior liberdade econômica, credibilidade nas instituições, estabilidade no mercado financeiro, facilidade para o fornecendo de crédito e para as operacionalizações financeiras neste mercado. 


\section{Referências}

ACEMOGLU, D.; JOHNSON, S.; ROBINSON, J.A. Institutions as a fundamental cause of long-run growth. In: AGHION, P.; DURLAUF, S. N. Handbook of economic growth. 2005.

AFRICANO, P. A.; MAGALHÃES, M. FDI and Trade in Portugal: A Gravity Analysis. FEP Working Papers, n.174, (abril), 2005.

AIZENMAN, J.; SPIEGEL M. M. Institutional Efficiency, Monitoring Costs, and the Investment Share of FDI. NBER Working Paper, No. 9324, 2002.

ALFARO, L.; KALEMLI-OZCAN, S.; VOLOSOVYCH, V. Why doesn't capital flow from rich to poor countries? An empirical investigation. The Review of Economics and Statistics, v. 90, p. 347-368, 2008

AMAL, M.; SEABRA, F. Determinantes do Investimento Direto Externo (IDE) na América Latina: Uma Perspectiva Institucional. EconomiA. v. 8, n. 2, p. 231-247, 2007.

ANDERSON, J. E.; VAN WINCOOP, E. Trade costs. Journal of Economic Literature, v. 42, n. 3, p. 691-751, 2004.

ARSLAN, A.; LARIMO, J.: Ownership strategy of multinational enterprises and the impacts of regulative and normative institutional distance: evidence from finnish foreign direct investments in central and eastern Europe. Journal of East West Business, v. 16, n. 3, p. 179-200, 2010.

ASIEDU, E. Foreign direct investment in Africa: the role of natural resources, market size, government policy, institutions and political instability. The World Economy, v.29, p. 63-77, 2006.

BCB - BANCO CENTRAL DO BRASIL. Sistema de séries temporais. Disponível em: <http://www. bcb.gov.br/?serietemp>. Acesso em: 10 out. 2013.

BÉNASSY-QUÉRÉ, A.; COUPET, M.; MAYER T. Institutional Determinants of Foreign Direct Investment. The World Economy, Reino Unido, v. 30, n.5, p. 764-782, 2007.

BENGOA, M.; SANCHEZ-ROBLES, B. Foreign direct investment, economic freedom and growth: new evidence from Latin America. European Journal of Political Economy. v. 19, p. 520-545. 2003.

BERRY, H.; GUILLÉN, M. F.; ZHOU, N. An institutional approach to cross-national distance. Journal of International Business Studies, v. 41, n. 9, p. 1460-1480, 2010.

BEVAN, A. A.; ESTRIN, S. The Determinants of foreign direct investment into European transition economies. Journal of Comparative Economics. v. 32, p. 775-787. 2004.

BLANCO, L. R. The Spatial Interdependence of FDI in Latin America. World Development. v. 40, n. 7, p. 1337-1351. 2012

BUCKLEY, P. J. CASSON, M. The future of the multinational enterprise. London: MacMillan, 116p, 1976.

CAMERON, A. C.; TRIVEDI, P. K. Microeconometrics Using STATA. College Station, Texas: Stata Press, 692 p., 2009.

CAMPOS, N. F.; KINOSHITA, Y. Why Does FDI Go Where it Goes? New Evidence from the Transition Economies. International Monetary Fund, Working Paper 03/228, 2003.

CEPAL - COMISSÃO ECONÔMICA PARAA AMÉRICA LATINA E O CARIBE. O investimento estrangeiro direto na América Latina e Caribe. Documento informativo 2011. Disponível em: $<\mathrm{http}: / /$ www.eclac.org/publicaciones/xml/1/46571/2012-183-LIEP-WEB.pdf>. Acesso em: 15 jul. 2013.

CEPII - CENTRE D'ESTUDES PROSPECTIVES ET D'INFORMATIONS INTERNATIONALES. Dados estatísticos: Databases GeoDist. Disponível em: <www.cepii.fr/CEPII/en/bdd_modele/ presentation.. sp? $\mathrm{id}=6>$. Acesso em Out/2013.

CHEDE, R. S. Determinantes institucionais do investimento direto externo. 2008. 99 f. Monografia (Graduação em Economia) - Centro Socioeconômico, Departamento de Ciências Econômicas, Universidade Federal de Santa Catarina, Florianópolis, 2008.

Estud. Econ., São Paulo, vol. 46, n.2, p. 281-310, abr.-jun. 2016

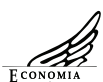


CLAESSENS, S.; VAN HOREN, N. Location decisions of foreign banks and institutional competitive advantage. Working Paper no 172. DNB, Amsterdam. 2008.

CUERVO-CAZURRA, A.; GENC, M. Transforming disadvantages into Advantages: developingcountry MNEs in the least developed countries. Journal of International Business Studies, v. 39, p. 957-979, 2008.

DAUDE, C., STEIN, E. The quality of institutions and foreign direct investment. Economics \& Politics, v. 19, n.3, p. 317-344, 2007.

DE GROOT, H.L.F.; LINDERS, G.J.M.; RIETVELD, P.; SUBRAMANIAN, U. The institutional determinants of bilateral trade patterns. Kyklos, v. 57, p. 103-123, 2004.

DEL BO, C. F. M. Foreign direct investment, exchange rate volatility and political risk. 2009. 32 p. Paper of Ph.D. Dissertation - Università Degli Studi, Milano. 2009.

DIAS, A. R. Determinantes do investimento direto externo para economias em desenvolvimento e em transição, 1996-2011. Existem diferenças para a América Latina e Caribe? 2014, p. 80. Dissertação (Mestrado em Economia do Desenvolvimento) - Faculdade de Administração, Contabilidade e Economia da Pontifícia Universidade Católica do Rio Grande do Sul, 2014.

DUNNING, J. H. Multinational enterprise and the global economy. Wokinghan, England: AddisonWesley, 1993.

DUNNING, J. H. Determinants of foreign direct investment: globalization induced changes and the role of FDI policies. Washington: World Bank. Annual Bank Conference on Development Economics, 2002.

DUNNING, J. H.; LUNDAN, S. M. Institutions and the OLI paradigm of the multinational enterprise. Asia Pacific Journal of Management, v.25, n.4, p.573-593, 2008.

FERNANDES, E. A. Investimento Direto Externo no Brasil: Efeitos no Crescimento, nas Exportações e no Emprego. Tese de doutorado. Departamento de Economia Rural (DER), Universidade Federal de Viçosa (UFV), 2006.

FMI - FUNDO MONETÁRIO INTERNACIONAL. Balance of payments and international investment position manual. 6 ed. Washington, D.C.: DRAFT, Statistic Department, 2008.

GLOBERMAN, S.; SHAPIRO, D. Global Foreign Direct Investment Flows: The Role of Governance Infrastructure. World Development. v. 30, n. 11, p. 1899-1919. 2002.

GREENE, W. H. Econometric Analysis. Pearson Education Inc., 6th edition. 2008.

HABIB, M.; ZURAWICKI, L. Corruption and foreign direct investment. Journal of International Business Studies n. 33, p. 291-307, 2002.

HERITAGE FOUNDATION. Index of economic freedom. Disponível em: < http://www.heritage.org/ index/explore>. Acesso em: 17 maio 2014.

HYMER, S. The international operations of national firms: a study of direct foreign investment. Ph. D. Dissertation. MIT: MIT Press, 1976.

JOHANSON, J.; VAHLNE, J-E. The Mechanism of Internationalisation. In: JOHANSON, J. et al. Internationalization, Relationships and Networks. Stockholm: Uppsala, p.83-95, 1994.

KAUFMANN, D.; KRAAY, A.; MASTRUZZI, M. Governance matters VIII: aggregate and individual governance indicators 1996-2008. Washington, D.C.: World Bank Policy Research, (Working Paper, 4978) 2009.

KOGUT, B.; SINGH, H. The effect of national culture on the choice of entry mode. Journal of International Business Studies, v. 19. n. 3, p. 411-432, 1988.

KOSTOVA, T. Success of the transnational transfer of organizational practices within multinational corporations. Unpublished doctoral dissertation, University of Minnesota, Minneapolis: MN, 1996.

LARIMO, J. Form of investment by Nordic firms in world markets. Journal of Business Research, v. 56, n. 10, p. 791-803, 2003.

Estud. Econ., São Paulo, vol. 46, n.2, p. 281-310, abr.-jun. 2016 
LINDERS, G. J. M. Intangible barriers to trade: the impact of institutions, culture, and distance on patterns of trade. Amsterdam: Thela Thesis Academic Publishing Services, 2006. (Tinbergen Institute Research Series, 371). 2006.

LUCAS, R. Why doesn't capital flow from rich to poor countries? The American Economic Review, v. 80, p. 92-96, 1990.

MENDONÇA, T. G. et al. Instituições e comércio bilateral de produtos agropecuários. Disponível em: $<$ http://anpec.org.br/encontro/2011/- inscricao/arquivos/0005e19ded7bc83bcfb76b1a75f118b75 ab.doc $>$. Acesso em: Set/2013.

MUDAMBI, R.; NAVARRA, P. Institutions and international business: A theoretical overview. International Business Review, v. 11, n. 1, p. 35-55, 2002.

MUDAMBI, R.; NAVARRA, P.; PAUL, C. Institutions and market reform in emerging economies: A rent-seeking perspective. Public Choice, forthcoming. 2002.

NONNENBERG, M. J. B.; MENDONÇA, M. J. C. Determinantes dos investimentos diretos externos em países em desenvolvimento. Estudos econômicos, São Paulo, v. 35, n. 4, p. 631-655, out./dez. 2005.

NORTH, D.C. Institutions, institutional change and economic performance. Cambridge: Cambridge University Press, 1990.

PAPAIOANNOU, E. What drives international financial flows? Politics, institutions and other determinants. Journal of Development Economics, v. 88, p. 269-281, 2009.

PENG, M. W.; SUN, L. S; PINKHAM, B.; CHEN, H. The Institution-based view as a third leg for a strategy tripod. Academy of Management Perspectives, v. 23, n. 3, p.63, 2009.

RAMIREZ, M. D. Economic and Institutional Determinants of FDI Flows to Latin America: A Panel Study. Trinity College Department of Economics, Working Paper 10-03, Maio de 2010.

ROBINSON, J.; TORVIK, R.; VERDIER, T. Political foundations of the resource curse. Journal of Development Economics, v. 79, p. 447-468, 2006.

RODRIK, D.; SUBRAMANIAN, A.; TREBBI, F. Institutions rule: the primacy of institutions over geography and integration in economic development. Journal of Economic Growth n. 9, p. 131165, 2004.

SANTOS, T. L. Determinantes do Investimento de Portfólio da União Européia: uma abordagem gravitacional. 2009. 60 f. Dissertação (Mestrado em Economia) - Universidade Federal de Santa Catarina - UFSC, 2009.

SANTOS SILVA, J. M. C.; TENREYRO, S. The log of gravity. The Review of Economics and Statistics, Cambridge, v. 88, n. 4, 2006.

SHEPHERD, B. Notes on the 'theoretical' Gravity model of international trade. Background paper for ARTNeT 2008 Capacity-Building Workshop for Trade Research: "Behind the Border" Gravity Modelling, Bangkok, 15-19 Dec. 2008.

UNCTAD. Transnational corporations, extractive industries and development. World Investment Report. United Nations, New York and Geneva, 2007.

VERNON, R. International Investment and International Trade in the Product Cycle. Quarterly Journal of Economics, v. 80, 1966.

WEEKS, D. V. Determinantes do investimento estrangeiro direto bilateral: uma abordagem do ambiente de negócios. 2014, p. 55. Tese (Doutorado em Economia Aplicada) - Escola Superior de Agricultura "Luiz de Queiroz", 2014.

WEI, S. How taxing is corruption to international investors? Review of Economics and Statistics, v. 82 , n. 1, p. 1-11, 2000.

WILLIAMSON, O. E. The new institutional economics: taking stock, looking ahead. Journal of Economic Literature, v. 38, n. 3, p. 595-613, 2000.

WORLD BANK. World Development Report 2005: A Better Investment Climate for Everyone. Washington: Oxford University Press, 2005. 
WORLD BANK. Worldwide Governance Indicators. Disponível em: < http://databank.worldbank.org/ data/reports.aspx?source=worldwide-governance-indicators $>$. Acesso em: 24 out. 2013.

XU, D.; SHENKAR, O. Institutional distance and the multinational enterprise. Academy of Management Review, v. 27, p. 608-618, 2002. 